\title{
СОЦИАЛЬНО-ПСИХОЛОГИЧЕСКИЕ ФАКТОРЫ РИСКА ЗАБОЛЕВАНИЯ ЗЛОКАЧЕСТВЕННЫМИ НОВООБРАЗОВАНИЯМИ: АКТУАЛЬНОСТЬ И ПЕРСПЕКТИВЫ ИССЛЕДОВАНИЯ
}

\section{SOCIO-PSYCHOLOGICAL RISK FACTORS FOR MALIGNANT NEOPLASMS: RELEVANCE AND PROSPECTS OF THE STUDY}

\section{Tsiring \\ Ya. Pakhomova \\ A. Vazhenin \\ M. Mironchenko}

Summary: Cancer is a disease that poses a threat to human life and health. There is no clear opinion on the influence of social and psychological factors on the development of cancer. This paper attempts to generalize and systematize the available data on the nature of malignant neoplasms. The analysis revealed that the most important psychosocial risk factors in the development of cancer are difficulties in expressing negative emotions, feelings of despair and helplessness in the face of difficulties, hopelessness as a specific reaction to stressful events, the presence of depressive states, increased levels of anxiety, the predominance of external locus of control and low significance of the value of health. Understanding the mechanisms of the impact of stressful events on the individual's psyche, studying the factors that influence the morbidity and survival of patients with cancer diagnosis, will help to identify the psychosomatic nature of the disease and show the existence of additional important predictors of survival of patients with malignant neoplasms.

Keywords:oncology, oncopsychology, malignant neoplasms, stress, difficult life situation.
Циринг Диана Александровна

д.псх.н., г.н.С., Томский государственный университет; профессор, Челябинский государственный университет

L-di@yandex.ru

Пахомова Яна Николаевна

к.nсх.н., н.с., Томский государственный университет; дочент, Челябинский государственный университет sizova159@yandex.ru

Важенин Андрей Владимирович

д.мед.н., гл.врач, Челябинский областной клинический центр онкологии и ядерной медицины

vav222@mail.ru

Миронченко Марина Николаевна к.мед.н., ст.н.С., Томский государственный университет; дочент, Южно-Уральский государственный медицинский университет (Челябинск), thoraxhir@mail.ru

Аннотация: Онкологическое заболевание является заболеванием, представляющим угрозу для жизни и здоровья человека. В вопросе влияния социальных и психологических факторов на развитие онкологического заболевания нет однозначного мнения. В данной работе предпринята попытка обобщения и систематизации имеющихся данных относительно природы злокачественных новообразований. В результате проведённого анализа было выявлено, что наиболее важными психосоциальными факторами риска в развитии рака являются сложности в выражении негативных эмоций, чувство отчаяния и ощущение собственной беспомощности перед трудностями, проявление безнадёжности как специфической реакции на стрессовые события, наличие депрессивных состояний, повышенный уровень тревожности, преобладание экстернального локуса контроля и низкая значимость ценности здоровья. Понимание механизмов воздействия стрессовых событий на психику индивида, изучение факторов, оказывающих влияние на заболеваемость и выживаемость пациентов с онкологическим диагнозом, позволят обозначить психосоматическую природу заболевания и показать существование дополнительных важных предикторов выживаемости пациентов со злокачественными новообразованиями.

Ключевые слова: онкология, онкопсихология, злокачественные новообразования, стресс, трудная жизненная ситуация.

особые требования к нему. В условиях необходимости эффективного разрешения негативных событий и явлений становится актуальным вопрос о стрессоустойчивости индивида. Одним людям в процессе преодоления инамический темп жизни, усиливающиеся процессы глобализации и информатизации, нестабильная социально-экономическая ситуация оказывают влияние на современного человека и предъявляют

1 Исследование выполнено при поддержке РФФИ (проект № 20-013-00824 «Психологические факторы риска заболевания злокачественными новообразованиями у женщин, проживающих в промышленном мегаполисе и сельской местности»). 
трудностей свойственны высокая эффективность, способность организовывать и регулировать свои поведение и деятельность, рациональное распределение собственных ресурсов, другим - ощущение беспомощности и невозможности своими силами изменить ситуацию и предсказать ход её развития. Особенно остро проблема стрессоустойчивости индивида и продуктивного совладания с трудными жизненными условиями проявляется в ситуациях, несущих угрозу для жизни и здоровья человека, в том числе при онкологическом заболевании.

Исследования психологических параметров у пациентов с онкологическими заболеваниями различных локализаций ведутся уже несколько десятков лет, однако интерес к этой теме у ученых всего мира не только не ослабевает, но и увеличивается.

Результаты исследований последних десятилетий выявили негативное влияние стрессовых событий на здоровье людей [1, 2, 4, 7, 10, 11 и другие]. В данных исследованиях учёными отмечается опосредованность заболеваемости и выживаемости индивидов с онкологическим диагнозом социальными и психологическими особенностями последних. Однако, определить конкретные социальные и психологические механизмы и факторы, приводящие к развитию злокачественных новообразований, учёным пока не удаётся, получаемые результаты являются неоднозначными и иногда противоречат друг другу.

Исходя из вышеизложенного, представляется важным и актуальным систематизировать имеющиеся в науке данные по проблеме социально-психологической детерминации онкологического заболевания.

Так, целью данной работы является выявление и теоретическое обоснование социально-психологических факторов заболевания злокачественными новообразованиями. Понимание механизмов воздействия стрессовых событий на психику индивида, изучение факторов, оказывающих влияние на заболеваемость и выживаемость пациентов с онкологическим диагнозом, позволят обозначить психосоматическую природу заболевания и показать существование дополнительных важных предикторов выживаемости пациентов со злокачественными новообразованиями.

Основными методами данного исследования выступили теоретический обзор и анализ литературных источников, методы систематизации и обобщения материала.

Психологические предпосылки развития злокачественных новообразований описаны в работах P. Revidi, H.J. Eysenck, L. Temoshok, Y. Chida, И.Г. Малкиной-Пых, М.Г. Ивашкиной, К.П. Балицкого, Н.В. Тарабриной и других. P. Revidi отмечает, что возникновению онкологических заболеваний способствуют склонность к депрессивным реакциям, сдержанность в проявлении эмоций, выраженные чувство вины и неуверенности в себе. Автор отмечает, что переживание длительного стресса и опыт психотравм могут привести к развитию злокачественных новообразований в сроки от 1 года до 15 лет [по 5].

Согласно данным исследования H.J. Eysenck, с возникновением ракового заболевания связаны такие особенности личности, как подавление гнева, тревоги, беспокойства и других эмоциональных реакций, ригидность установок, чувство отчаяния, депрессия, самопожертвование. Во взаимоотношениях такие люди склонны избегать открытых конфликтов, конформны, испытывают сложности в отстаивании своей точки зрения, терпеливы и услужливы. При совладании с трудностями им свойственно чувство беспомощности. H.J. Eysenck отмечает, что человеку с указанными характеристиками с большей вероятностью грозит появление злокачественных новообразований, а также в случае заболевания раком более быстрая смерть, чем у людей с другими личностными особенностями [9].

B работе L. Temoshok предпринята попытка создания интегративной модели, учитывающей психологические и физиологические характеристики личности с онкологическим заболеванием и особенности процесса совладания с болезнью. В данной модели автор старается сгладить имеющиеся противоречия между в понимании природы рака. Также L. Temoshok приводит данные относительно факторов, детерминирующих образование злокачественных опухолей. К ним относятся ощущения безнадёжности и собственной беспомощности в стрессовых ситуациях, трудности в выражении эмоций [12].

По данным Y. Chida и соавторов, психосоциальные факторы влияют на возникновение злокачественного новообразования у изначально здоровых людей. Непродуктивные стратегии совладающего поведения, переживание негативных эмоциональных состояний, низкое качество жизни выступают не только в роли факторов, повышающий риск заболевания раком, но и влияют на выживаемость пациентов с уже диагностированным онкологическим заболеванием [8].

В исследовании психологического профиля онкологических больных отмечаются ряд личностных особенностей, характерных для большинства людей с онкологическими заболеваниями. Данные особенности рассматриваются также в качестве факторов риска развития злокачественных новообразований: наличие ригидных установок и стереотипов относительно здоровья и болезни, доминирующая детская позиция в коммуникации, превалирование экстернальности локуса контроля, низкая значимость ценности здоровья [2, 3].

В исследовании Н.В. Тарабриной и соавторов отмечается важная роль таких социальных факторов, как природные катастрофы, смерть близких людей, несчастные 
случаи, которые существенно влияют на развитие онкологических заболеваний. Кроме того, авторы отмечают, что «стрессы, связанные с рождением детей, с переживаниями угрозы для жизни детей или их смертью, относятся к числу серьезных факторов, ведущих у женщин к развитию рака молочной железы» $[1,4]$. Говоря о семье как социальном факторе риска развития онкологического заболевания и в контексте выживаемости пациентов с раком, следует упомянуть результаты исследования О.Н. Шаровой. Полученные автором данные свидетельствуют о том, что опыт семейной жизни, как положительный, так и отрицательный (развод, смерть одного из супругов), играет более позитивную роль в продуктивности совладания с ситуацией онкологического заболевания, нежели отсутствие такого опыта [6].

Обобщая рассмотренные психологические факторы риска развития злокачественных новообразований, в качестве основных выделим: сложности в выражении негативных эмоций и их вербализации, ощущение беспомощности и чувство отчаяния, проявления безнадёжности как реакции на стресс, наличие депрессивных состояний и повышенный уровень тревожности. Говоря о социальных факторах, провоцирующих появление и развитие онкологического заболевания, отметим роль стрессовых жизненных событий, низкий уровень социальной поддержки, стрессы семейных взаимоотношений.

Таким образом, согласно приведённым результатам исследований, стресс, определённые характеристики личности и особенности социальной среды могут способ- ствовать возникновению онкологического заболевания. Изучение психосоциальных факторов риска развития злокачественных новообразований представляет не только научный интерес, но и практический, так как позволяет разработать реабилитационные психологические программы, способствующие улучшению качества жизни пациентов с онкологией и повысить их выживаемость.

Вместе с тем, важно подчеркнуть, что изучать психологические факторы в отрыве от других, очевидно влияющих на состояние пациента с данным диагнозом, не верно. Однако, количество исследований, выполненных совместно специалистами различных наук (медиками, биологами, психологами, психотерапевтами, социологами и др.), чрезвычайно незначительно. Кроме того, результаты исследований влияния психологических факторов на развитие онкозаболеваний неоднозначны. Важным условием плодотворного поиска решения проблемы природы онкологического заболевания является объединение исследований различных научных дисциплин, изучающих человека и его здоровье на разных уровнях. Проведённый теоретический обзор исследований, посвящённых социально-психологическим факторам риска заболевания злокачественными новообразованиями, послужит основой дальнейшего эмпирического изучения личностных особенностей онкопациентов в рамках системного пролонгированного изучения психологических, медицинских и социальных факторов выживаемости онкобольных, проживающих в промышленном мегаполисе и сельской местности.

\section{ЛИТЕРАТУРА}

1. Ж Журавлев А.Л., Тарабрина Н.В., Генс Г.П., Коробкова Л.И., Ворона О.А., Падун М.А. Роль психосоциальных стрессоров в динамике угрожающих жизни болезней (на примере рака молочной железы) // Фундаментальные науки - медицине. М.: «Слово», 2005. С. $42-44$.

2. Ивашкина М.Г. Психологические особенности личности онкологических больных : дис. . . . канд. психол. наук. М., 1998.

3. Малкина-Пых И.Г. Психосоматика. М.: Эксмо, 2008. 1024 с.

4. Тарабрина Н.В. Посттравматический стресс у больных угрожающими жизни (онкологическими) заболеваниями // Консультативная психология и психотерапия, 2014, № 1. С. 40-63;

5. Усманова Е.Б. Психологические факторы качества жизни больных с опухолевым поражением костей : дисс. . . . канд. пс. наук: 19.00.04. СПб, 2016.

6. Шарова 0.Н. Стрессоустойчивость как показатель медико-психолого-социальной адаптации лиц с онкологическими заболеваниями // Живая психология. 2017. Том 4. № 2. С. 157-174. doi: 10.18334/Ip.4.2.38386.

7. Avison W.R., Gotlieb I.H. (Eds.). Stress and mental health. Contemporary issues and prospects for the future. New York: Plenum Press, 1994. P. 15-73.

8. Chida Y., Hamer M., Wardle J., Steptoe A. Do stress-related psychosocial factors contribute to cancer incidence and survival? // Nat. Clin. Pract. Oncol. 2008. № 5(8). P. 466-475.

9. Eysenck H. Cancer, personality and stress: prediction and prevention // Advances in Behaviour Research and Therapy. 1994. № 16. P. 167-215.

10. House J.S., Landis K.R., Umberson D. Social relationships and health // Science. 1988. № 241. P. 540-545.

11. Lehto U.-S., Ojanen M., Kellokumpu-Lehtinen P. Predictors of quality of life in newly diagnosed melanoma and breast cancer patients // Annals of Oncology. № 16, Issue 5. P. 805-816. D0l: https://doi.org/10.1093/annonc/mdi146.

12. Temoshok L. Personality, coping style, emotion and cancer: towards an integrative model // Cancer Surv. 1987. №. 6. P. 545-567.

( Ц Циринг Диана Александровна (L-di@yandex.ru), Пахомова Яна Николаевна (sizova159@yandex.ru), Важенин Андрей Владимирович (vav222@mail.ru), Миронченко Марина Николаевна (thoraxhir@mail.ru).

Журнал «Современная наука: актуальные проблемы теории и практики» 